in vivo $33: 1581-1592(2019)$

doi:10.21873/invivo.11640

\title{
Predictive Value of Endoplasmic Reticulum Stress Markers in Low Ejection Fractional Heart Failure
}

\author{
RAMAZAN SABIRLI ${ }^{1}$, AYLIN KOSELER $^{2}$, NESTEREN MANSUR $^{3}$, ALI ZEYTUNLUOGLU $^{4}$, \\ GIZEM TUKENMEZ SABIRLI ${ }^{5}$, IBRAHIM TURKCUER ${ }^{6}$ and ISMAIL DOGU KILIC ${ }^{7}$ \\ ${ }^{1}$ Servergazi State Hospital, Department of Emergency Medicine, Denizli, Turkey; \\ ${ }^{2}$ Department of Biophysics, Pamukkale University Medical Faculty, Denizli, Turkey; \\ ${ }^{3}$ Department of Biotechnology, Institute of Health Sciences, \\ Acibadem Mehmet Ali Aydinlar University, Istanbul, Turkey; \\ ${ }^{4}$ Department of Electronic and Automation, Denizli Vocational School of Technical Sciences, \\ Pamukkale University, Denizli, Turkey; \\ ${ }^{5}$ Department of Pediatrics, Pamukkale University Medical Faculty, Denizli, Turkey; \\ ${ }^{6}$ Department of Emergency Medicine, Pamukkale University Medical Faculty, Denizli, Turkey; \\ ${ }^{7}$ Department of Cardiology, Pamukkale University Medical Faculty, Denizli, Turkey
}

\begin{abstract}
Background/Aim: Endoplasmic reticulum (ER) stress plays a critical role in the development of cardiac hypertrophy and heart failure. Heart failure is a crucial health problem that affects 23 million people worldwide, causes approximately 2.4 million people to be hospitalized every year in the USA, and leads to the death of more than 300,000 people. In this study, we aimed to investigate the clinical significance of ER stress markers and the predictive value of acute decompensated heart failure in patients with low ejection fraction heart failure (ADHF). Patients and Methods: This is a prospective case control study. The data included laboratory parameters pertaining to patients with ADHF in the emergency service and lipid parameters obtained during their admission to the hospital. In addition, the same parameters obtained from the control group patients with chronic heart failure $(\mathrm{CHF})$ during their routine polyclinic control were recorded in the data set. Admission time to the hospital and length of hospital stay were included in the data. The levels of glucose regulated protein (GRP78), protein kinase RNA-like endoplasmic reticulum kinase (PERK), and $C / E B P$ homologous protein $(C H O P)$ in peripheral blood
\end{abstract}

This article is freely accessible online.

Correspondence to: Dr. Ramazan Sabirli, Servergazi State Hospital, Department of Emergency Medicine, Bereket Avenue, Bereket Street 1, 20000 Merkezefendi/Denizli, Turkey. Tel: +90 5387344298. e-mail: ramazan_sabirli@hotmail.com

Key Words: Endoplasmic reticulum stress, heart failure, acute decompensated heart failure. serum obtained from the patients and the control group were measured using the ELISA method. Results: Serum GRP78 concentration was lower in the HF group $(p=0.003)$ compared to the control. The median value of serum PERK concentration in the HF group was higher than that of the control group (573 pg/ml, IQR=477.5-650 vs. $495.5 \mathrm{pg} / \mathrm{ml}$, $I Q R=294-648$, respectively) $(p=0.001)$. However, there were no statistically significant differences in GRP78 and PERK serum concentrations between ADHF and CHF subgroups. Receiver operating characteristic (ROC) curve analysis showed greater area under the curve (AUC) for the serum GRP78 levels of the healthy individuals (AUC $=0.748,95 \%$ $C I=0.681-0.814, p=0.0003)$. The serum GRP78 level was found to be $80 \%$ sensitive and $70 \%$ specific at $147.5 \mathrm{pg} / \mathrm{ml}$ ( $p=0.0003)$ for distinguishing healthy individuals from $\mathrm{HF}$ patients. In the ADHF subgroup, there was a moderate correlation between hospitalization time and serum CHOP concentrations (Spearman rho=0.586 and $p=0.001$ ). Conclusion: High GRP78 serum concentration may protect the patient from ER stress. In addition, the serum PERK level is high in patients with $H F$, whereas it is insufficient in predicting acute decompensation. CHOP may be useful in predicting the length of hospital stay in patients with $A D H F$.

Heart failure (HF) is a clinical syndrome caused by the structural or functional impairment of ventricular filling or the ejection of blood. There is no single diagnostic test for $\mathrm{HF}$, because it is a clinical diagnosis largely based on a history and physical examination of patients. HF is divided into two main groups based on the status of ejection fraction (EF) in the 2013 ACCF/AHA Heart Failure Guidelines: EFpreserved $\mathrm{HF}$ (HFpEF) and $\mathrm{HF}$ with low $\mathrm{EF}$ (HfrEF), EF>50 
in $\mathrm{HfpEF}$ and $\mathrm{EF} \mathrm{H} 40 \%$ in HfrEF (1) and approximately $80 \%$ of $\mathrm{HF}$ are hospitalized due to acute decompensation (2). While $70 \%$ of acute decompensated heart failure (ADHF) is an acute exacerbation of chronic conditions, $15-20 \%$ of it emerges as a new incident of HF. Acute decompensation leads to disorders including acute coronary syndrome, myocarditis, acute or progressive valve pathologies, cardiomyopathies (tachycardia induced, recent onset dilated KMP, takotsubo, etc.), uncontrolled hypertension, dietary disorders, non-compliance with medical therapy, electrolyte disorders, hypo- or hyper-thyroidism, atrial fibrillation, systemic infections, pulmonary embolism, anemia, and worsening of renal failure (3).

The endoplasmic reticulum (ER) has an important role in the regulation of protein and lipid production in the cell, protein folding and control, post-translational modification of proteins, and calcium storage $(4,5)$. The processing of proteins in the ER lumen is initiated by a signal peptide of about 25 amino acids. When this signal peptide is detected and the protein is transported to the ER lumen, proteins are folded evenly with the helper proteins called chaperones and folding enzymes $(6,7)$. Conditions such as viral infections, oxidative stress, calcium metabolism disorders and hyperlipidemia lead to deterioration of ER homeostasis $(8,9)$. When ER stress occurs, the unfolded and improperly folded proteins are deposited in the ER lumen. In response to the stress occurring during this process, ER activates the unfolded protein response (UPR) signal transduction pathway (10).

ER stress occurs in four main stages: i) Protein kinase RNA-like ER kinase (PERK) phosphorylation and new protein synthesis, phosphorylation and protein translation of alpha subunit eukaryotic initiation factor-2 (elF-2 $\alpha$ ) protein . ii) stimulation of Glucose Regulated Protein (GRP78) and other chaperone proteins. iii) eradication of improperly folded or unfolded proteins by the ubiquitin-proteosome system in ER. iv) activation of apoptosis pathways if ER stress persists severely for a long period of time (11).

PERK is one of the ER transmembrane proteins. The PERK protein is separated from the GRP78 protein and then phosphorylates itself by dimerization. It initiates and regulates responses to stress (12). The GRP78 is considered to be the protein which is active in UPR and can be specifically stimulated in ER stress. The GRP78 protein acts as a quality control system. It monitors the folding protein and ensures that the protein is transported when it is properly folded. Overexpression of GRP78 reduces ER stress and cardiac damage (13-14). C/EBP homologous protein (CHOP) is a pro-apoptotic protein, whose expression is regulated by the PERK-activating transcription factor 4 (ATF4), the ATF6, and the inositol-requiring enzyme 1 (IRE1) pathways. CHOP protein plays a role especially in apoptosis (15).

ER stress plays a critical role in the development of cardiac hypertrophy and heart failure. Heart failure is a crucial health problem that affects 23 million people worldwide, causes approximately 2.4 million people to be hospitalized every year in the USA, and leads to the death of more than 300,000 people (16). In this study, we aimed to investigate the clinical significance of ER stress markers and the predictive value of acute decompensation in patients who have low ejection fraction $\mathrm{HF}$.

\section{Patients and Methods}

Study population. Prior to the study, ethical approval numbered 60116787-020/13220 was obtained from Pamukkale University Ethics Committee. The study is a prospective, case-control study. The study was conducted between January 2019 and April 2019 and includes patients who applied to Pamukkale University Hospital emergency service with heart failure complaints (1-3) and patients diagnosed with HF who visited Pamukkale University Hospital Cardiology Polyclinic for routine follow-up controls. The patient group and the healthy control group were informed about the study and a written consent form was obtained from all patients who chose to participate in it. The control group consisted of healthy patients who did not have a known chronic or acute disease and were not using any related drugs.

Based on the participant inclusion and exclusion criteria, the subjects were divided into two groups as the HF group and healthy group (Control Group). The sociodemographic characteristics of the patients as well as their information including causes of decompensation (if the patient have decompensation findings), comorbid diseases, drugs used, duration of admission to the hospital (duration of the symptoms) and length of hospital stay were recorded in the data.

HF group: This group included patients who had routine followups due to HF in the cardiology outpatient clinic or patients that who have applied to emergency medicine department due to heart failure symptoms or not. They were diagnosed with known low EF deficiency and had no exclusion criteria. The diagnoses were checked according to the 2013 ACCF/AHA Guideline for the Management of Heart Failure (1). They all consented to participate in the study and were included in the heart HF group.

Healthy group (control): This group consists of people with no known history of acute, subacute or chronic disease. They were not using any drugs, and they provided written consent to participate in the study.

The exclusion criteria included the diagnosis of acute pulmonary embolism, kidney and liver failure, pregnancy, history of chronic inflammatory disease (e.g. rheumatic disease, autoimmune disease), the presence of a known cancer diagnosis, chronic obstructive pulmonary disease, asthma, history of cerebrovascular disease, $\mathrm{EF}>40$, clinical treatment of ongoing cardiogenic shock and having infectious diagnosis. In addition, if the lipid profile of a patient was examined on a different day from the one that the patient applied to the emergency service, the patient was excluded from the study.

Echocardiography. Echocardiographic examinations were performed with ultrasound systems (Philips iU22 and Terason $3200 \mathrm{t}$ ) by using $1-5 \mathrm{MHz}$ frequency ranged curvilinear probe according to the American Society of Echocardiography Guidelines (17). An independent cardiologist who was not included in the study performed echocardiograms on the patients and the healthy group, 
and the patients' systolic pulmonary arterial pressure (PAP) value, ejection fraction, and detected heart valve pathologies were recorded in the patient form.

Noninvasive assessment of pulmonary artery systolic pressures (sPAP) was achieved by the measurement of right ventricular systolic pressure (RVSP), which was derived from the peak systolic velocity of the tricuspid regurgitation and obtained with continuouswave $(\mathrm{CW})$ Doppler using the modified Bernoulli equation: $\Delta \mathrm{P}=4 \times \operatorname{Vmax}^{2}(18)$. The ejection fraction was calculated using the modified Simpson's rule, from a long axis view and four short axis views at different levels of the left ventricule (LV) of the heart.

Blood samples and laboratory parameters. The HF group parameters of the complete blood count (0 hour) routinely tested at the time of admission to the emergency service cardiology polyclinic, $\mathrm{C}$ reactive protein (CRP) values, and cardiac markers (high sensitive troponin $\mathrm{T}$ (hsTnT), CKMB) were recorded in the data set. The HF group patients' admission date to the cardiology service ( 0 days) and the CHF group's lipid parameters (e.g. total cholesterol, triglyceride, HDL, LDL, VLDL), which were routinely examined during appointments to the cardiology outpatient clinic $(0$ hour), were recorded in the data set as well.

Blood samples of size 3-cc for lipid parameters were drawn from the HF group patients when they came to the outpatient clinic and from the patients who required hospitalization when they were hospitalized. In addition, the same amount of blood samples were drawn from the control group samples for the measurement of ER stress parameters when they were included in the study. After the blood samples were drawn into dry tubes and centrifuged at 5000 rpm for $10 \mathrm{~min}$, the serum section was separated, and ER stress markers were examined using the Enzyme-Linked Immunosorbent Assay (ELISA) method. Furthermore, 3-cc blood samples from the control group were drawn into the dry tubes, 3-cc blood samples were drawn into EDTA tubes, and then all the laboratory parameters were examined in the same laboratory using the same methods, which were applied for the HF group.

ELISA for the detection of serum GRP78, CHOP and PERK. Serum levels of GRP78, CHOP and PERK were measured using the commercially available ELISA kits, namely Human Glucose Regulated Protein 78 (GRP78) ELISA Kit (SL2048Hu; SunLong Biotech, Hangzhou, Zhejiang, PR China). Human C/EBP homologous protein (CHOP) ELISA Kit (SL2631Hu; Sunlong Biotech, Hangzhou, Zhejiang, PR China), and Human PERK (Phospho Extracellular Signal Regulated Kinase) ELISA Kit (MyBioSource.com, MBS014568, USA), respectively. ELISA assays were performed according to the manufacturers' protocols. The detection rates of GRP78, CHOP, and PERK were 16 pg/ml, 6 pg/ml, and $18.75 \mathrm{pg} / \mathrm{ml}$, respectively.

Data analysis. Given the lack of reference studies, the effect size calculated for this study came out to be medium-high $(\mathrm{f}=0.5)$ following the power analysis performed according to the assumptions. As such, it was determined that at least 220 people (at least 110 people per group) should be included in the study to obtain $95 \%$ power with $95 \%$ confidence.

Data were analyzed using SPSS statistical software package. While mean values, standard deviations, and medians (IQR) were provided for continuous variables, categorical variables were presented in number and percentage. Mann-Whitney $U$-test and
Kruskal Wallis variance analysis were used to compare the independent group differences when the parametric test assumptions were not met. Added to that, the relationships between continuous variables were analyzed by Spearman correlation analysis and the differences between categorical variables were analyzed by Chisquare analysis. Furthermore, receiver operating characteristic (ROC) curve analysis was used to assess the discriminant performance for the markers under investigation. The $p$-value $<0.05$ was considered statistically significant in all analyses.

\section{Results}

Between January 2019 and June 2019, 912 patients were admitted to the emergency service with respiratory distress and 195 of these patients were diagnosed with HF. Out of these 195 patients, 34 refused to participate in the study. Eight patients were diagnosed with HFpEF. Sixty-two patients could not be asked if they wanted to participate in the study because the emergency service was busy at that time. Furthermore, 21 patients were excluded from the study because they fitted one of the exclusion criteria. Sixty patients were included in the HF group from emergency medicine department (Figure 1). In the same period, of the 117 patients who had been diagnosed with HfrEF and applied to the cardiology polyclinic for routine control, 42 patients refused to participate in the study. Fifteen patients were excluded from the study because they fit the exclusion criteria. Sixty patients were included in the HF group from cardiology policlinic. In total 120 patients who were diagnosed HfrEF were included in HF group (Figure 2). In addition, 120 patients who met the age and sex criteria were included in the control group.

As a result of the power analysis based on the results we obtained in the study, the effect size of the serum ER stress marker concentrations for the differences between the two groups was medium-high ( $\mathrm{f}=0.5$ ) and while the power level observed in the study for this effect size was $95 \%$, the reliability level was $96.4 \%$.

The HF group included $68(56.66 \%)$ male and 52 $(43.34 \%)$ female participants. The gender distribution in the control group was $52(43.33 \%)$ males 68 (56.67\%) females. The mean ages of the HF and control group were $58.43 \pm 2.14$ and $57 \pm 1.41$ years, respectively (Table I). In the HF group a total of $32(26.7 \%)$ patients were NHYA class1, 28 (23.3\%) patients were NHYA Class 2, $50(41.7 \%)$ patients were NHYA Class 3, and 10 (8.3\%) patients were NHYA Class 4. Valvular pathologies and comorbidities of the patients are presented in Table I.

The systolic PAP median value was found to be significantly lower in the HF group, compared to the control (15 $\mathrm{mmHg}, \mathrm{IQR}=14-17$ vs. $30 \mathrm{mmHg} \mathrm{IQR}=15.25-40$; $p=0.001)$. The median value of $\mathrm{EF}$ was 60 (IQR=60-60) in the control group and 30 (IQR=25-37.25) in the HF group (Table I). There were significant statistical differences were 


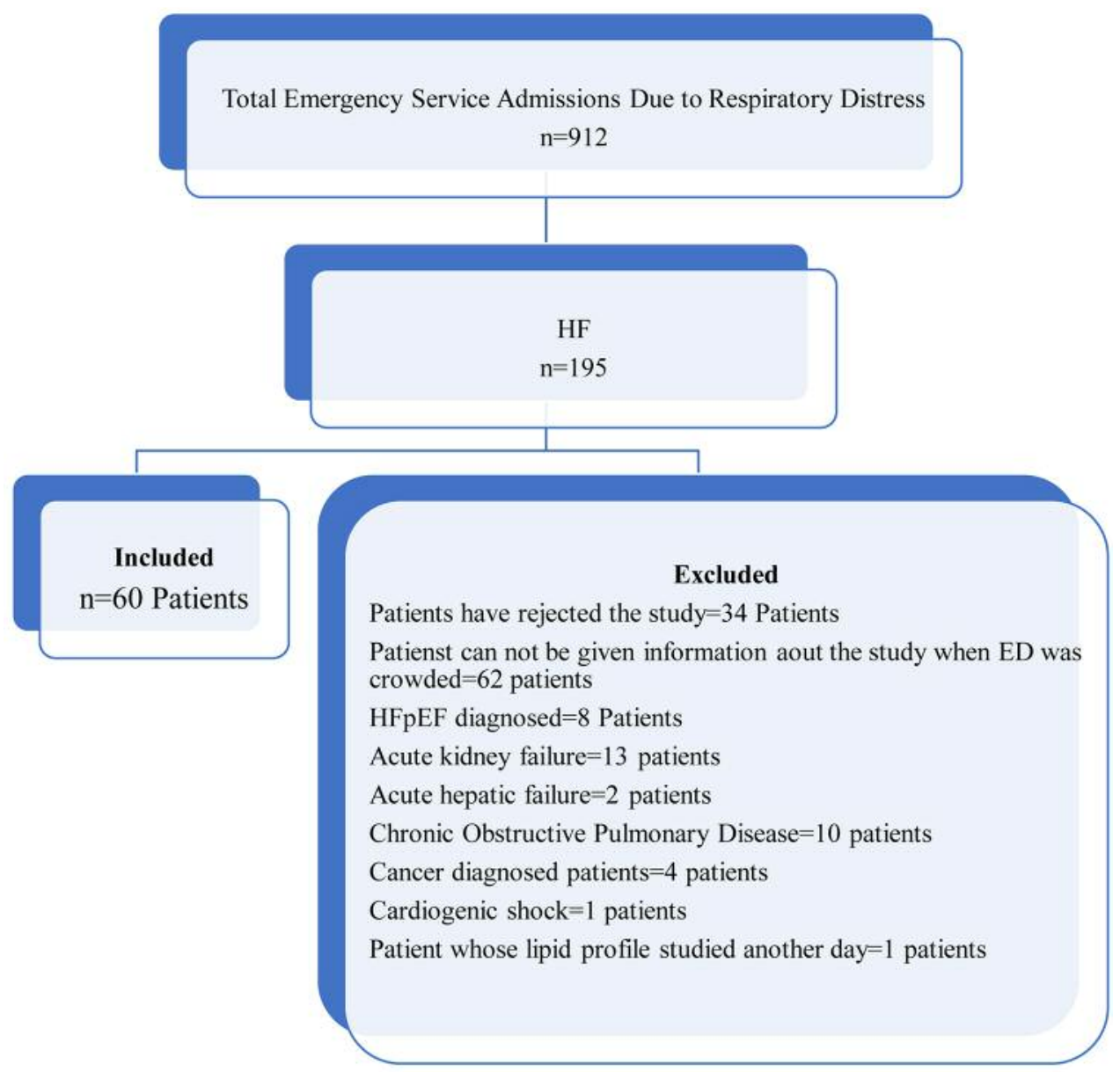

Figure 1. Patients with heart failure $(H F)$ who are included from Emergency Medicine Department. ED, Emergency department; HFpEF, heart failure with preserved ejection fraction.

found regarding the EF value between the $\mathrm{HF}$ and control groups $(p=0.00001)$ (Table I).

A total of $44(36.66 \%)$ patients in the HF group did not receive any diuretic treatment. Twenty-eight $(23.34 \%)$ patients were only using furosemide while $10(8.33 \%)$ patients were only using spironolactone. In addition, 38 $(31.66 \%)$ patients were using furosemide and spironolactone together, while $2(1.67 \%)$ patients were taking thiazide diuretic drugs. Ninety-eight patients $(81.67 \%)$ in the HF group were using a beta-blocking agent (Table II).

Among the laboratory parameters that were evaluated in the HF and control groups, C-reactive protein (CRP; $p=0.001$ ), creatinin kinase isoenzyme $\mathrm{MB}$ (CKMB; $p=0.012)$, white blood cell (WBC; $p=0.044)$ and high sensitive troponin T (hsTnT; $p=0.0001)$ were higher in the HF group. On the contrary, total cholesterol $(p=0.011)$, low density lipoprotein (LDL; $p=0.002$ ) and high density lipoprotein (HDL; $p=0.0001$ ) were lower in the HF compared to the control group (Table III).
As shown in Table IV, the cause of decompensation in the acute decompansed subgroup (ADHF) was determined as acute coronary syndrome in 24 patients $(41.38 \%$ ), noncompliance to treatment in 28 patients $(48.27 \%)$ and acute cardiomyopathy in 6 patients $(10.35 \%)$. In addition, the ADHF group, the median value of the length of time from onset of shortness of breath to hospital admission was 7 days $(I Q R=3-19)$, and the median value of the period from hospitalization to discharge was 5 days (IQR=3-9).

When ER stress markers were examined, the median value of serum PERK concentration in the control group was found to be $495.5 \mathrm{pg} / \mathrm{ml}$ (IQR=294-648), $573 \mathrm{pg} / \mathrm{ml}(\mathrm{IQR}=477.5-650)$ in the HF group. The median value of GRP78 concentration was determined as $258.5 \mathrm{pg} / \mathrm{ml}(\mathrm{IQR}=154-347)$ in the control group and $89 \mathrm{pg} / \mathrm{ml}(\mathrm{IQR}=72.75-178.75)$ in the HF group. The median value of CHOP concentration was determined as 47 $\mathrm{pg} / \mathrm{ml}(\mathrm{IQR}=30.25-75)$ in the control group and $39 \mathrm{pg} / \mathrm{ml}$ $(\mathrm{IQR}=28-71)$ in the HF group (Table V). When all HF patients were compared to the control group, the serum PERK 


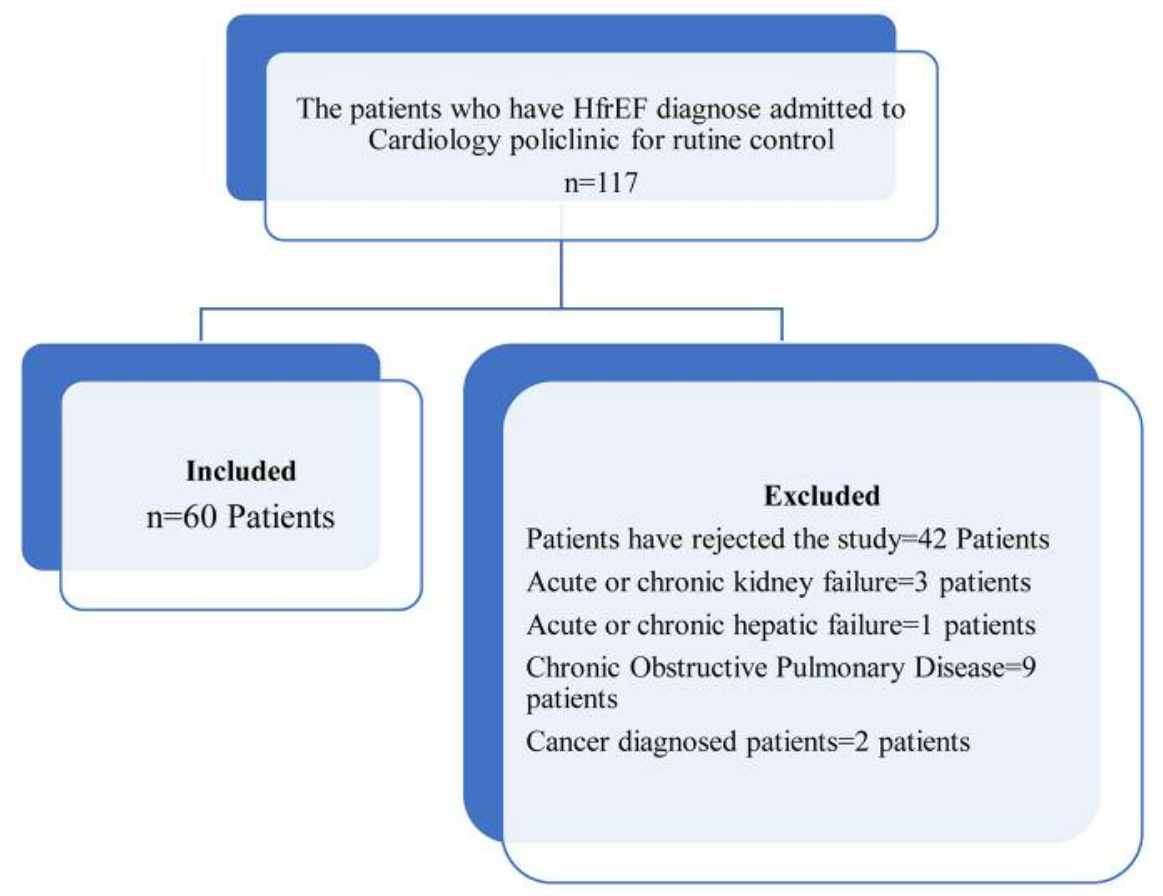

Figure 2. Flow chart of the patients from cardiology policlinic, who were included into the heart failure (HF) group. HfrEF, Heart failure with reduced ejection fraction.

concentration was higher in the HF group than the control group (573 pg/ml, IQR=477.5-650 vs. $495.5 \mathrm{pg} / \mathrm{ml}, \mathrm{IQR}=294-648 ; \mathrm{p}$ $=0.001)$. The serum GRP78 concentration was significantly lower in the HF than control group $(89 \mathrm{pg} / \mathrm{ml}, \mathrm{IQR}=72.75$ 178.75 vs. $258.5 \mathrm{pg} / \mathrm{ml}, \mathrm{IQR}=154-347 ; p=0.0003$ ). According to Table V, CHOP concentration did not differ between the two groups $(39 \mathrm{pg} / \mathrm{ml}, \mathrm{IQR}=28-71$ vs. $47 \mathrm{pg} / \mathrm{ml}, \mathrm{IQR}=30.25-75$; $p=0.069)$. ROC analysis showed greater AUC for the serum GRP78 levels of the healthy individuals (AUC $=0.748,95 \%$ $\mathrm{CI}=0.681-0.814, p=0.0003)$. The serum GRP78 level at 147.5 $\mathrm{pg} / \mathrm{ml}$ was found to be $80 \%$ sensitive and $70 \%$ specific ( $p=0.0003)$ for distinguishing healthy individuals from HF patients (Figure 3). ROC analysis showed greater AUC for the serum GRP78 levels of the HF patients $(A U C=0.629,95 \%$ $\mathrm{CI}=0.557-0.702$ vs, $p=0.001)$. Furthermore, the serum PERK level at $494.5 \mathrm{pg} / \mathrm{ml}$ was found to be $70 \%$ sensitive and $50 \%$ specific at $494.5 \mathrm{pg} / \mathrm{ml}$ level $(p=0.001)$ (see Figure 4).

When ER stress markers were examined in subgroups, the median value of serum PERK concentration in the CHF subgroup, was found to be $540.5 \mathrm{pg} / \mathrm{ml}(\mathrm{IQR}=467-662)$ in the CHF subgroup, and $594 \mathrm{pg} / \mathrm{ml}(\mathrm{IQR}=504-634)$ in the ADHF subgroup. The median value of GRP78 concentration was determined as $90 \mathrm{pg} / \mathrm{ml}(\mathrm{IQR}=72-172)$ in the $\mathrm{CHF}$ subgroup, and $87.5 \mathrm{pg} / \mathrm{ml}(\mathrm{IQR}=75-198)$ in the ADHF subgroup. The median value of $\mathrm{CHOP}$ concentration was determined as $36 \mathrm{pg} / \mathrm{ml}(\mathrm{IQR}=28-74.5)$ in the CHF subgroup and $41.5 \mathrm{pg} / \mathrm{ml}(\mathrm{IQR}=27.5-60)$ in the ADHF subgroup (Table VI). When all the patients in the subgroups and control group were compared, the serum PERK concentration was significantly lower in the control group than in the ADHF and CHF subgroup (492.23 pg/ml, IQR=294-648 vs. 571.83 $\mathrm{pg} / \mathrm{ml}, \mathrm{IQR}=467-662$ and $569.71 \mathrm{pg} / \mathrm{ml}, \mathrm{IQR}=504-634$; $p=0.0001)$.Serum GRP78 concentration was significantly higher in the control group than the ADHF and CHF group (277.23 pg/ml, IQR=154-347 vs. $176.53 \mathrm{pg} / \mathrm{ml}, \mathrm{IQR}=72-172$ and $255.03 \mathrm{pg} / \mathrm{ml}, \mathrm{IQR}=75-198 ; p=0.002)$. Among the control group, the CHF subgroup and the ADHF subgroup no statistical differences in serum CHOP concentrations $(p=0.179)$ were found (Table VI).

The serum GRP78 level was significantly higher in the control group compared to the CHF and ADHF subgroups ( $p=0.003$ and $p=0.009$, respectively). However, there were no statistically significant differences in GRP78 and PERK serum concentrations between the ADHF and CHF subgroups ( $p=0.777$ and $p=0.350$ respectively) (Table VI).

Systolic PAP, ejection fraction, serum CKMB, and hsTnT values were not strongly correlated with serum PERK, GRP78 and CHOP concentrations (Pearson correlation coefficient $<0.30$ in all parameters). Moreover, there was a moderate correlation between hospitalization time and serum CHOP concentrations in the ADHF group (Spearman rho= 0.586 and $p=0.001$ ). 
Table I. Baseline parameters of the heart failure $(H F)$ and the healthy control groups.

\begin{tabular}{|c|c|c|c|c|}
\hline & & Control, n (\%) & $\mathrm{HF}, \mathrm{n}(\%)$ & $p$-Value \\
\hline \multirow[t]{2}{*}{ Gender } & Male & $52(43.33 \%)$ & $68(56.66 \%)$ & $0.268 *$ \\
\hline & Female & $68(56.67 \%)$ & $52(43.34 \%)$ & \\
\hline Age, years $($ Mean $\pm S D)$ & & $57 \pm 1.41$ & $58.43 \pm 2.14$ & $0.583 * *$ \\
\hline \multirow[t]{4}{*}{ NHYA class } & Class 1 & - & $32(26.7 \%)$ & \\
\hline & Class 2 & - & $28(23.3 \%)$ & \\
\hline & Class 3 & - & $50(41.7 \%)$ & \\
\hline & Class 4 & - & $10(8.3 \%)$ & \\
\hline \multirow[t]{5}{*}{ Aortic valve regurgitation } & Grade 0 & 30 & $72(60.0 \%)$ & \\
\hline & Grade 1 & & $42(35.0 \%)$ & \\
\hline & Grade 2 & & $6(5.0 \%)$ & \\
\hline & Grade 3 & & 0 & \\
\hline & Grade 4 & & 0 & \\
\hline \multirow[t]{5}{*}{ Mitral valve regurgitation } & Grade 0 & 30 & $14(11.7 \%)$ & \\
\hline & Grade 1 & & $60(50.0 \%)$ & \\
\hline & Grade 2 & & $42(35.0 \%)$ & \\
\hline & Grade 3 & & $4(3.3 \%)$ & \\
\hline & Grade 4 & & 0 & \\
\hline \multirow[t]{5}{*}{ Tricuspid valve regurgitation } & Grade 0 & 30 & $26(21.7 \%)$ & \\
\hline & Grade 1 & & $64(53.3 \%)$ & \\
\hline & Grade 2 & & $18(15.0 \%)$ & \\
\hline & Grade 3 & & $12(10.0 \%)$ & \\
\hline & Grade 4 & & 0 & \\
\hline Systolic PAP (mmHg), Median (IQR) & & $15(14-17)$ & $30(15.25-40)$ & $0.00001 * *$ \\
\hline Ejection fraction, Median(IQR) & & $60(60-60)$ & $30(25.00-37.25)$ & $0.0001 * *$ \\
\hline History of hypertension & & $56(45.16 \%)$ & $52(43.33 \%)$ & $0.525^{*}$ \\
\hline History of diabetes mellitus & & $24(19.35 \%)$ & $30(25.0 \%)$ & $0.391 *$ \\
\hline History of hyperlipidemia & & $12(9.67 \%)$ & $10(8.33 \%)$ & $0.625^{*}$ \\
\hline
\end{tabular}

${ }^{*} p$-Value is derived from Fisher exact test. ${ }^{* *} p$-Value is derived from Mann Whitney $U$-test. SD, Standard deviation; NHYA, New York Heart Association; PAP, pulmonary artery pressure; IQR, interquartile range.

\section{Discussion}

This case control study investigated the predictive value of ER stress markers in HF including PERK, GRP78, and CHOP serum concentrations for acute and chronic HF. The results showed that serum PERK concentration was found to be higher in the HF group and the serum GRP78 concentration was found to be significantly lower in the HF group, compared to the control. However, there were no statistically significant differences between the serum GRP78 and PERK concentrations of the ADHF and CHF groups. In addition, the results revealed that serum GRP78 concentration was $80 \%$ sensitive and $70 \%$ specific at $147.5 \mathrm{pg} / \mathrm{ml}$ level.

To the best of our knowledge, there has been no prior research investigating the clinical value of ER stress markers in chronic or acute HF in humans. While one study in the literature examined the ER stress markers in patients who received return of spontaneous circulation (ROSC) and who did not after cardiopulmonary resuscitation, there are several studies investigating ER stress in patients who died due to ischemic stroke $(19,20)$.
Table II. Drug use data of heart failure $(H F)$ patients.

\begin{tabular}{lc}
\hline & HF group, $\mathrm{n}(\%)$ \\
\hline Diuretic use & \\
None & $44(36.66 \%)$ \\
Spironolactone & $10(8.33 \%)$ \\
Furosemide & $28(23.34 \%)$ \\
Thiazide & $2(1.67 \%)$ \\
Combine & $36(30.0 \%)$ \\
Anti-hypertensive drug use & \\
None & $22(18.33 \%)$ \\
Beta blocker only & $26(21.67 \%)$ \\
Combination (Beta blocker plus other & $72(60.0 \%)$ \\
anti-hypertensive drugs) & \\
Anti-hyperlipidemic drug use & \\
None & $94(78.33 \%)$ \\
Statin & $26(21.67 \%)$ \\
\hline
\end{tabular}

Building ischemia-reperfusion or cardiac arrest models in animals, several studies have been conducted to investigate the change of ER stress markers at the tissue level $(21,22)$. 
Table III. Laboratory parameters of the the heart failure (HF) and healthy control groups.

\begin{tabular}{|c|c|c|c|c|c|}
\hline & \multicolumn{2}{|c|}{ Control group } & \multicolumn{3}{|c|}{ HF group } \\
\hline & Mean \pm SD & Median (IQR) & Mean \pm SD & Median (IQR) & $p$-Value \\
\hline CRP (mg/dl) & $0.59 \pm 1.69$ & $0.175(0.109-0.371)$ & $1.88 \pm 3.62$ & $0.482(0.225-1.734)$ & $0.001 *$ \\
\hline CKMB $(\mu \mathrm{g} / 1)$ & $2.37 \pm 1.00$ & $2.49(1.38-3.25)$ & $11.54 \pm 41.89$ & $3.13(1.99-4.17)$ & $0.012 *$ \\
\hline hsTnT $(\mu \mathrm{g} / \mathrm{l})$ & $0.006 \pm 0.005$ & $0.005(0.004-0.007)$ & $0.34 \pm 1.22$ & $0.019(0.08-0.958)$ & $0.0001 *$ \\
\hline WBC & $7.89 \pm 2.18$ & $7.59(6.29-9.48)$ & $9.64 \pm 3.68$ & $8.93(6.89-11.0)$ & $0.044 *$ \\
\hline Total cholesterole $(\mathrm{mg} / \mathrm{dl})$ & $193.3 \pm 40.19$ & $219.5(190.5-252.7)$ & $163.11 \pm 44.29$ & $161.5(127-191.75)$ & $0.011 * *$ \\
\hline $\mathrm{LDL}(\mathrm{mg} / \mathrm{dl})$ & $116.33 \pm 36.30$ & $109(89.5-138.25)$ & $96.66 \pm 32.56$ & $97.5(73.25-119.25)$ & $0.002 * *$ \\
\hline HDL (mg/dl) & $52.53 \pm 15.79$ & $52(41.75-60)$ & $39.56 \pm 13.36$ & $37(30-46.75)$ & $0.0001 *$ \\
\hline VLDL (mg/dl) & $25.36 \pm 9.98$ & $25.50(18.75-30.50)$ & $27.23 \pm 13.69$ & $22.5(16-34.25)$ & $0.918^{*}$ \\
\hline Triglyceride (mg/dl) & $126.16 \pm 49.53$ & $128(91.25-151.25)$ & $135.25 \pm 69.14$ & $111(80-172)$ & $0.949 *$ \\
\hline
\end{tabular}

${ }^{*} p$-Values are derivated from Mann Whitney $U$-test. ${ }^{* *} p$-Values are derivated from independent samples T test. IQR, Interquartile range; CRP, C-reactive protein; CKMB, creatine kinase-muscle/brain; hsTnT, high-sensitive troponin T; WBC, white blood cell; LDL, low density lipoprotein; HDL, high density lipoprotein; VLDL, very low density lipoprotein.

Table IV. Clinical data of patients with acute decompensated heart failure.

\begin{tabular}{|c|c|c|c|}
\hline & $\mathrm{n}(\%)$ & Median (IQR) & Spearman correlations (rho) \\
\hline \multicolumn{4}{|l|}{ Cause of decompensation } \\
\hline Acute coronary sydrome & $24(41.38)$ & & \\
\hline Non-compliance with treatment & $28(48.27)$ & & \\
\hline Acute cardiomyopathy & $6(10.35)$ & & \\
\hline \multirow[t]{3}{*}{ Duration of symptoms (days) } & & $7(3-19)$ & $0.099^{\mathrm{a}}$ \\
\hline & & & $0.031^{b}$ \\
\hline & & & $0.158^{\mathrm{c}}$ \\
\hline \multirow[t]{3}{*}{ Duration of hospitalization (days) } & & $5(3-9)$ & $0.051^{\mathrm{a}}$ \\
\hline & & & $0.387^{b}$ \\
\hline & & & $0.586^{\mathrm{c}}, *$ \\
\hline
\end{tabular}

${ }^{a}$ rho value is derivated from Spearman Correlations and it shows correlation between duration of hospitalization and serum PERK levels. ${ }^{b}$ rho value is derivated from Spearman Correlations and it shows correlation between duration of hospitalization and serum GRP78 levels. ${ }^{c}$ rho value is derivated from Spearman Correlations and it shows correlation between duration of hospitalization and serum CHOP levels. * $p$-value for rho is 0.001 . IQR, Interquartile range.

Several studies have indicated that GRP78 induction is cardioprotective and neuroprotective, whereas PERK protein is protective against pressure overload-induced $\mathrm{HF}$ and lung remodeling, and the $\mathrm{CHOP}$ protein is effective in sensitizing cells to apoptosis by suppressing of the Bcl-2 protein family that contains pro-apoptotic and apoptotic proteins. (15, 23-26).

The effects of PERK protein in the development of atherosclerosis, chronic hypertension, and cardiac hypertrophy were discussed in a recent review study in which ER stress was described as a new therapeutic target in cardiovascular diseases (27). In a study conducted with rats, it was found that cardiac dysfunction and fibrosis were more frequently observed in rats whose cardiac specific PERK protein was destroyed. In another study, it was reported that PERK expression in transverse aortic constriction-induced cardiac hypertrophy in rats was still increased after 4 weeks, while 4- phenylbutyric acid (4-PBA) reduced ER stress. In addition, it was emphasized that the detection of ER stress by the PERK protein correctly protects the heart from hypertrophy and dysfunction, and it was stated that PERK protein is not essential for cardiac function in stress-free periods but is important for adaptation to cardiac stress in situations in which chronic pressure increases (28). In a study in which a cardiac arrest model was established in rats, PERK activation was found to be different in peripheral organs. Following cardiac arrest, the highest ER stress response was observed in the liver and kidney. In this study, no markers were examined in peripheral blood (29). In another study that predicted the survival of ER stress markers in non-hospital cardiac arrest, serum PERK values were examined and found to predict 24$h$ survival. The median value of serum PERK concentration was found to be higher in patients who survived $24 \mathrm{~h}$ (19). 
in vivo $33: 1581-1592(2019)$

Table V. Endoplasmic reticulum (ER) stress parameters of the Control and heart failure (HF) groups.

\begin{tabular}{|c|c|c|c|c|c|}
\hline & \multicolumn{2}{|c|}{ Control group } & \multicolumn{3}{|c|}{ HF group } \\
\hline & Mean \pm SD & Median (IQR) & Mean \pm SD & Median (IQR) & $p$-Value \\
\hline PERK (pg/ml) & $492.23 \pm 233.2$ & $495.5(294-648)$ & $570.77 \pm 136.12$ & $573(477.5-650)$ & 0.001 \\
\hline GRP78 $(\mathrm{pg} / \mathrm{ml})$ & $277.23 \pm 165.38$ & $285.5(154-347)$ & $215.78 \pm 307.62$ & $89(72.75-178.75)$ & 0.0003 \\
\hline $\mathrm{CHOP}(\mathrm{pg} / \mathrm{ml})$ & $78.83 \pm 75.28$ & $47(30.25-75)$ & $66.49 \pm 66.65$ & $39(28-71)$ & 0.069 \\
\hline
\end{tabular}

$p$-Values are derived from Mann Whitney $U$-test. SD, Standard deviation; IQR, interquartile range; PERK, protein kinase RNA-like endoplasmic reticulum kinase; GRP78, glucose regulated protein; CHOP C/EBP homologous protein.

Table VI. Endoplasmic reticulum (ER) stress markers of the groups.

\begin{tabular}{|c|c|c|c|c|c|c|c|}
\hline & \multicolumn{2}{|c|}{ Control group } & \multicolumn{2}{|c|}{ CHF subgroup } & \multicolumn{2}{|c|}{ ADHF subgroup } & \multirow{2}{*}{$p$-Value } \\
\hline & Mean \pm SD & Median (IQR) & Mean \pm SD & Median (IQR) & Mean \pm SD & Median (IQR) & \\
\hline PERK (pg/ml) & $492.23 \pm 233.2$ & $495.5(294-648)$ & $571.83 \pm 161.48$ & $540.5(467-662)$ & $569.71 \pm 106.27$ & $594(504-634)$ & $\begin{array}{l}0.0001 * \\
0.350^{* *}\end{array}$ \\
\hline GRP-78 (pg/ml) & $277.23 \pm 165.38$ & $285.5(154-347)$ & $176.53 \pm 240.15$ & $90(72-172)$ & $255.03 \pm 360.64$ & $88(75-198)$ & $\begin{array}{l}0.002^{*} \\
0.003^{* * *} \\
0.009^{\dagger} \\
0.777^{\dagger \dagger}\end{array}$ \\
\hline CHOP (pg/ml) & $78.83 \pm 75.28$ & $52(30.25-75.00)$ & $60.05 \pm 54.05$ & $36(28.0-74.5)$ & $72.93 \pm 77.16$ & $41.5(27.5-60.0)$ & $0.179 *$ \\
\hline
\end{tabular}

* $p$-Value derived from Kruskal-Wallis test. ${ }^{* *} p$-Value is derived from Kruskal-Wallis test, and refers to the comparison between ADHF and CHF subgroups. ${ }^{* *} p$-Value is derived from Kruskal-Wallis test and refers to the comparison between Control and CHF subgroups. ${ }^{\dagger} p$-Value is derived from Kruskal-Wallis test and $p$-value shows analyse results between Control and ADHF subgroups. $\dagger^{\dagger} p$-Value is derived from Kruskal-Wallis test and $p$-value shows analyse results between and ADHF and CHF subgroups. CHF, Chronic heart failure; ADHF, acute decompensation; SD, standard deviation; IQR, interquartile range; PERK, protein kinase RNA-like endoplasmic reticulum kinase; GRP78, glucose regulated protein; CHOP, C/EBP homologous protein.

In our study, higher serum PERK concentrations in the HF group compared to the control group showed that ER stress increased in HF patients in parallel with the literature. No statistically significant differences were found in serum PERK concentrations between the ADHF and CHF subgroups, indicating that PERK values were not as effective as we anticipated in predicting acute decompensation. There is no research that has offered a cut-off value by examining PERK concentration in peripheral blood. That serum PERK concentration was of $70 \%$ sensitivity and $50 \%$ specificity at $494.5-\mathrm{pg} / \mathrm{ml}$ levels suggests that this cut-off value may be useful for distinguishing heart failure patients. ER stress response is known to occur at the tissue level in a very short period of time (30), while the serum PERK value is considered to be lower than the peak concentration in the long run. Duan et al. have shown that the GRP78 positive cells were detected at the peak volume approximately in the 9th hour in the ischemic tissue when ER stress occurs. Compared with the control, GRP78-positive cells increase in $4 \mathrm{~h}$ up to 4 days after ischemia (20). It was also considered that a similar rise and normalization process could be seen in PERK. Considering that the median value of the time elapsed between respiratory distress and referral to the emergency service was 5 days, it was hypothesized that PERK might be useful in the short term for ER stress studies such as in the case of acute coronary syndrome, and it would not be valuable in predicting acute decompensation in chronic HF.

GRP78 is a chaperone protein that plays an important role in ER stress. There are studies reporting an increase in GRP78 expression in ER stress at the tissue level (31-33). GRP78 induction is also known to have cardioprotective and neuroprotective properties (14). In a study conducted on muscle cell lines, it was found that GRP-94, similar to GRP78, reduced cardiomyocyte necrosis in ischemia simulation (26). In another study, it was suggested that proteosome-induced cardiomyocyte death was prevented by GRP78 and pharmacological induction of GRP78 could prevent proteosome-induced cardiac tissue destruction. It was also reported that the induction of BiP/GRP78 in the ER-stress pathway inhibits hyperoxia and tunamycin-induced apoptosis. BiP (GRP78) inducer X (BIX), a molecular chaperone 


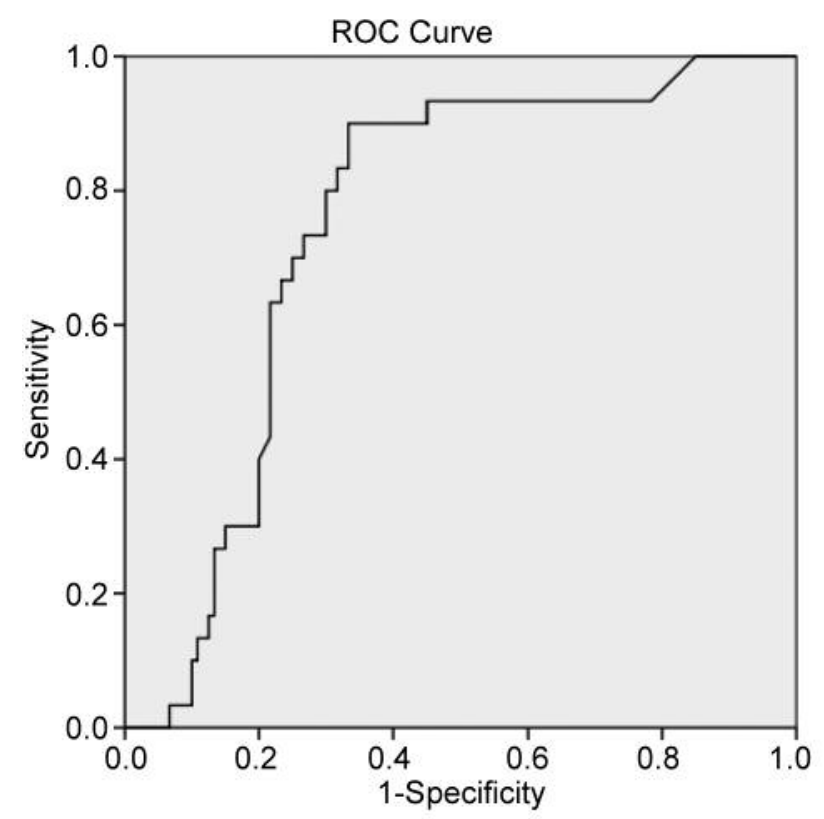

Diagonal segments are produced by ties

Figure 3. Receiver operating characteristic (ROC) curve analysis chart of glucose regulated protein GRP78 levels; heart failure $(H F)$ group vs. control group.

inducing agent, was reported to protect neurons from ER stress (23). In their study on retinal cells, Inokuchi et al. asserted that BIX could be used as a therapeutic agent in retinal diseases caused by ER stress (34). In a review by Minamino et al. on treatment targets addressing ER stress in cardiovascular diseases, it was stated that the induction of GRP78 could be useful in preventing cardiovascular diseases (14).

In a recent study, it was revealed that GRP78 overexpression inhibited synoviocyte apoptosis in the synovial fluid samples of patients with rheumatoid arthritis, which is known as a chronic inflammatory process, and synovicyte proliferation and angiogenesis were found to increase in rats with osteoarthritis with repeated intra-articular BIX (32). In a study conducted on chronic viral hepatitis B patients, no statistically significant differences were found in GRP78 levels examined in peripheral blood samples of the patient and healthy groups (35). Moreover, Ardic et al. have examined the prognostic value of ER stress markers in patients who were admitted to emergency service with cardiac arrest, and demonstrated that GRP78 concentrations did not have an impact on ROSC, 24-h, and 1- to 3-month survival periods. Except for the current study, there has been no research investigating the diagnostic value of GRP78 levels in peripheral blood samples of patients with HF. The serum GRP78 level was found to be higher in the control group in our study. Although the level of GRP78 does not represent the

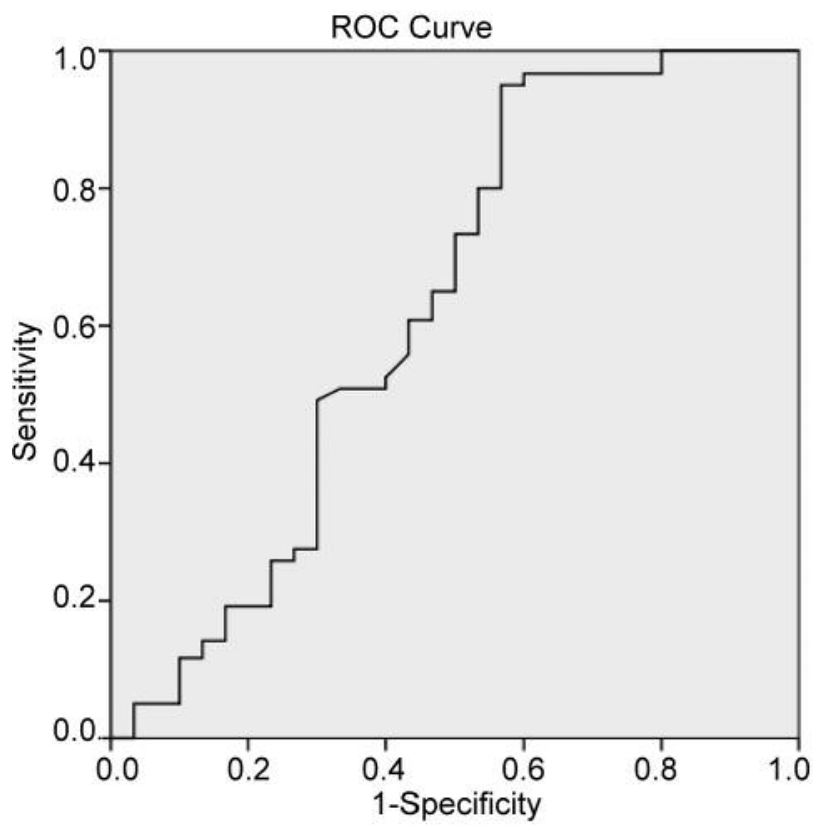

Figure 4. Receiver operating characteristic (ROC) curve analysis of protein kinase RNA-like endoplasmic reticulum kinase (PERK) levels; heart failure $(H F)$ group vs. control group.

level of GRP78 in the cardiac tissue, the high level of GRP78 in the peripheral blood seems to protect the individual from ER stress in the normal physiological state (19). This is the first study that offered a cut-off value of GRP78 concentration in peripheral blood. The proposed cut-off for serum GRP78 concentration $(147.5-\mathrm{pg} / \mathrm{ml})$ was of $80 \%$ sensitivity and $70 \%$ specificity, suggesting it value may be useful for the discrimination of healthy individuals from HF patients.

UPR is activated after various activators inhibit ER stress. The expression of GRP78 and other chaperone proteins increases after UPR activation. The PERK protein is activated by autophosphorylation, the $\operatorname{eIF}^{2 \alpha} \mathrm{Ser}^{51}$ protein is also phosphorylated, and these two events affect the synthesis of protein by reducing protein stress. The autophosphorylation of PERK protein plays an important role in providing homeostasis to ER stress (25). HF is also one of the conditions in which ER homeostasis is impaired and stress responses occur.

The $\mathrm{eIF}^{2 \alpha} \mathrm{Ser}^{51}$ protein of the PERK protein activates the ATF4 protein of the $\mathrm{eIF}^{2 \alpha} \mathrm{Ser}^{51}$ protein. In previous studies, the ATF4 protein has been proven to activate the proapoptotic protein, CHP and cardiac hypertrophy and $\mathrm{HF}$ occur when ER stress is too severe or too long. This results in the activation of the apoptotic pathway $(36,37)$. In a study evaluating ER stress regulation of the non-canonical pathway, inhibition of the expression of the CHOP protein 
was found to reduce ER stress and protect the patient from cardiac hypertrophy and HF (38). It was proven that the inhibition of the Prostatic androgen repressed message-1 (PARM-1) protein, a type of transmembrane protein in saltsensitized rats, increases PERK, ATF6 and CHOP expression, which triggers cardiac hypertrophy and HF (39). In their study of $\mathrm{CHOP}$ protein ablation in rats, $\mathrm{Fu}$ et al. suggested that $\mathrm{CHOP}$ protein play a role in the development of cardiac hypertrophy of HF. In a study conducted with rats using an acute mesenteric ischemia model, it was shown that CHOP expression increased in ischemic tissue (37). Serum CHOP protein concentration was found to be effective in predicting survival time in patients who were brought to the emergency service due to non-hospital cardiac arrest. In our study, we found that serum CHOP concentration was not different in the HF and control groups. It has been shown in many studies that beta-blocker agents prevent cardiac remodeling $(40,41)$.

$\mathrm{Ni}$ et al. found that ER chaperones and apoptosis decreased in rats treated with beta-blockers, and it was suggested that blocking of beta-blockers' remodeling could happen through ER stress suppression (42). In a study of autoimmune cardiomyopathy-created rabbits, beta1 receptor induction was found to increase ER stress (43). In a recent review, it was emphasized that beta-blocking agents reduce ER stress and that the use of statin group medication also reduced ER stress and apoptosis (27). Although it has been shown that CHOP increased in animal experiments, we think that this result may have been obtained due to differences in drug use and immunity status in humans. Considering that $81.6 \%$ of the total HF is a beta-blocker agent and that $21.6 \%$ of patients use statin group drugs, we think this might have contributed to the findings, in which no differences in CHOP concentrations were found between the control group and $\mathrm{HF}$ groups. CHOP may be useful in predicting the length of hospital stay, although it does not have a promising value in the prediction of acute decompensation since ER is effective in the later period of stress.

There are some limitations to the current study. The sample size of our study is small, although sufficient power is reached. However, this study informs future research that should be conducted with larger sample sizes. Patients applying to hospitals with acute decompensation complaints differ in periods from symptom onset to hospitalization processes, resulting in timing confusions regarding the examination of the serum ER stress marker level per hour. Given that the marker levels of patients were examined at one time, we were not able to see increasing or decreasing marker levels in the following processes. Because of the very high frequency of drug use that prevents remodeling, ER stress marker level differences could not be investigated between patients who used and did not use drugs. In our study, the number of patients with NHIA Class 4 HF was low, preventing us from forming conclusions about the clinical predictive value of ER stress markers in advanced HF.

\section{Conclusion}

As a result, the findings of this study suggest that GRP78 has high serum concentration in cases of ER stress, resulting in the protection of the patient from ER stress. The findings suggest that the serum PERK level is high in ER stress HF patients, but it is insufficient to predict acute decompensation. Moreover, serum PERK levels may be predictive in cases with shorter follow-up periods such as in the case of acute coronary syndrome. In patients with $\mathrm{HF}$, CHOP may be useful in predicting the length of hospital stay in acute decompensated heart failure.

\section{Author Contributions}

Conception: Ramazan Sabirli; Study design: Ramazan Sabirli, Aylin Koseler and Ismail Dogu Kilic; Funding: Aylin Koseler; Materials: Nesteren Mansur, Ismail Dogu Kilic, Ali Zeytunluoglu, Gizem Tukenmez Sabirli; Data collection and processing: Nesteren Mansur and Ali Zeytunluoglu; Literature review: Ramazan Sabirli, Gizem Tukenmez Sabirli and Ibrahim Turkcuer; Writer: Ramazan Sabirli and Aylin Koseler; Critical review: Ismail Dogu Kilic.

\section{References}

1 Yancy CW, Jessup M, Bozkurt B, Butler J, Casey DE Jr, Drazner MH, Fonarow GC, Geraci SA, Horwich T, Januzzi JL, Johnson MR, Kasper EK, Levy WC, Masoudi FA, McBride PE, McMurray JJ, Mitchell JE, Peterson PN, Riegel B, Sam F, Stevenson LW, Tang WH, Tsai EJ and Wilkoff BL: 2013 ACCF/AHA guideline for the management of heart failure: a report of the American College of Cardiology Foundation/American Heart Association Task Force on Practice Guidelines. J Am Coll Cardiol 62: e147239, 2013. PMID: 23747642. DOI: 10.1016/j.jacc.2013.05.019

2 Gheorghiade M, Vaduganathan M, Fonarow GC and Bonow RO: Rehospitalization for heart failure: problems and perspectives. $\mathrm{J}$ Am Coll Cardiol 61: 391-403, 2013. PMID: 23219302. DOI: 10.1016/j.jacc.2012.09.038

3 Meyer TE: Approach to acute decompensated heart failure in adults, 2018. Available at: https://www.uptodate.com/contents/ approachto-acute-decompensated-heart-failure-in adults? search=Approach $\%$ 20 to $\% 20$ acute $\% 20$ decompensated $\% 20$ heart $\% 20$ failure $\% 20 \mathrm{in} \% 20 \mathrm{ad}$ ults\&source=search_result\&selectedTitle $=1 \sim 150 \&$ usage_type=defa ult\&display_rank=1 (Accessed May 05, 2019)

4 Schwarz DS and Blower MD: The endoplasmic reticulum: Structure, function and response to cellular signaling. Cell Mol Life Sci 73: 79-94, 2016. PMID: 26433683. DOI: 10.1007/s00018015-2052-6

5 Walter P and Ron D: The unfolded protein response: from stress pathway to homeostatic regulation. Science 334: 1081-1086, 2011. PMID: 22116877.

6 Braakman I and Hebert DN: Protein folding in the endoplasmic reticulum. Cold Spring Harb Perspect Biol 5: a01320, 2013. PMID: 23637286. DOI: 10.1101/cshperspect.a013201 
7 Braakman I and Bulleid NJ: Protein folding and modification in the mammalian endoplasmic reticulum. Annu Rev Biochem 80: 71-99, 2011. PMID: 21495850. DOI: 10.1146/annurev-biochem062209-093836

8 Kim I, Xu W and Reed JC: Cell death and endoplasmic reticulum stress: disease relevance and therapeutic opportunities. Nat Rev Drug Discov 7: 1013-1030, 2008. PMID: 19043451 DOI: $10.1038 / \mathrm{nrd} 2755$

9 Maly DJ and Papa FR: Druggable sensors of the unfolded protein response. Nat Chem Biol 10: 892-901, 2014. PMID: 25325700. DOI: $10.1038 /$ nchembio. 1664

10 Zhang K: Endoplasmic reticulum stress response and transcriptional reprogramming. Front Genet 5: 460, 2015. PMID: 25709614. DOI: $10.3389 /$ fgene. 2014.00460

11 Luo B and Lee AS: The critical roles of endoplasmic reticulum chaperones and unfolded protein response in tumorigenesis and anticancer therapies. Oncogene 32: 805-818, 2013. PMID: 22508478. DOI: $10.1038 /$ onc .2012 .130

12 Harding HP, Zhang Y, Bertolotti A, Zeng H and Ron D: Perk is essential for translational regulation and cell survival during the unfolded protein response. Mol Cell 5: 897-904, 2000. PMID: 10882126

13 Snap E: Endoplasmic reticulum biogenesis. In: The biogenesis of cellular organelles. Mullins C (ed.), Boston, Springer, pp 63 95, 2005.

14 Minamino T, Komuro I and Kitakaze M: Endoplasmic reticulum stress as a therapeutic target in cardiovascular disease. Circ Res 107: 1071-1082, 2010. PMID: 21030724. DOI: 10.1161/ CIRCRESAHA.110.227819

$15 \mathrm{Li} \mathrm{Y,} \mathrm{Guo} \mathrm{Y,} \mathrm{Tang} \mathrm{J,} \mathrm{Jiang} \mathrm{J} \mathrm{and} \mathrm{Chen} \mathrm{Z:} \mathrm{New} \mathrm{insights} \mathrm{into} \mathrm{the}$ roles of CHOP-induced apoptosis in ER stress. Acta Biochim Biophys Sin (Shanghai) 46(8): 629-640, 2014. PMID: 25016584. DOI: $10.1093 / \mathrm{abbs} / \mathrm{gmu} 048$

16 Bui AL, Horwich TB and Fonarow GC: Epidemiology and risk profile of heart failure. Nat Rev Cardiol 8: 30-41, 2011. PMID: 21060326. DOI: $10.1038 /$ nrcardio.2010.165

17 Lang RM, Bierig M, Devereux RB, Flachskampf FA, Foster E, Pellikka PA, Picard MH, Roman MJ, Seward J, Shanewise JS, Solomon SD, Spencer KT, Sutton MS, Stewart WJ and Chamber Quantification Writing Group: Recommendations for chamber quantification: a report from the American Society of Echocardiography's Guidelines and Standards Committee and the Chamber Quantification Writing Group, developed in conjunction with the European Association of Echocardiography, a branch of the European Society of Cardiology. J Am Soc Echocardiogr 18: 14401463, 2005. PMID: 16376782. DOI: 10.1016/j.echo.2005.10.005

18 Greiner S, Jud A, Aurich M, Hess A, Hilbel T, Hardt S, Katus HA and Mereles D: Reliability of noninvasive assessment of systolic pulmonary artery pressure by Doppler echocardiography compared to right heart catheterization: analysis in a large patient population. J Am Heart Assoc 3: e001103, 2014. PMID: 25146706. DOI: 10.1161/JAHA.114.001103

19 Ardic S, Yilmaz S, Demir S, Dogramaci S, Altuntas G, Imamoglu M, Mentese A and Turedi S: Endoplasmic reticulum stress markers are of no value in predicting cardiopulmonary resuscitation success and survival in out-of hospital cardiac arrest: A nested case-control study. Turk J Emerg Med 19: 5863, 2019. PMID: 31065605. DOI:10.1016/j.tjem.2018.12.001

20 Duan S, Wang J, Wang J, Xu R, Zhao J and Wang D: Ischemia induces endoplasmic reticulum stress and cell apoptosis in human brain. Neurosc Lett 475: 132-135, 2010. PMID: 20347 937. DOI: $10.1016 /$ j.neulet.2010.03.058

21 Gupta MK, Tahrir FG, Knezevic T, White MK, Gordon J, Cheung JY, Khalili K and Feldman AM: GRP78 interacting partner Bag5 Responds to ER stress and protects cardiomyocytes from ER stress-induced apoptosis. J Cell Biochem 117: 18131821, 2016. PMID: 26729625. DOI: $10.1002 /$ jcb.25481

22 Montie HL, Kayali F, Haezebrouck AJ, Rossi NF and Degracia DJ: Renal ischemia and reperfusion activates the eIF2 alpha kinase PERK. Biochim Biophys Acta 1741: 314-324, 2005. PMID: 15936177. DOI: 10.1016/j.bbadis.2005.04.007

23 Kudo T, Kanemoto S, Hara H, Morimoto N, Morihara T, Kimura $\mathrm{R}$, Tabira T, Imaizumi K and Takeda M: A molecular chaperone inducer protects neurons from ER stress. Cell Death Differ 15: 364-375, 2008. PMID: 18049481. DOI: 10.1038/sj.cdd.4402276.

$24 \mathrm{Xu}$ D, Perez RE, Rezaiekhaligh MH, Bourdi M and Truog WE: Knockdown of ERp57 increases BiP/GRP78 induction and protects against hyperoxia and tunicamycin-induced apoptosis. Am J Physiol Lung Cell Mol Physiol 297: L44-51, 2009. PMID: 19411306. DOI: 10.1152/ajplung.90626.2008

25 Liu X, Kwak D, Lu Z, Xu X, Fassett J, Wang H, Wei Y, Cavener DR, $\mathrm{Hu} \mathrm{X}$, Hall J, Bache RJ and Chen Y: Endoplasmic reticulum stress sensor PERK protects against pressure overload induced heart failure and lung remodeling. Hypertension 64: 738-744, 2014. PMID: 24958502. DOI: 10.1161/HYPERTENSION AHA.114.03811

26 Vitadello M, Penzo D, Petronilli V, Michieli G, Gomirato S, Menabò R, Di Lisa F and Gorza L: Overexpression of the stress protein Grp94 reduces cardiomyocyte necrosis due to calcium overload and simulated ischemia. FASEB J 17: 923-925, 2003. PMID: 12670879. DOI: 10.1096/fj.02-0644fje

27 Wang S, Binder P, Fang Q, Wang Z, Xiao W, Liu W and Wang $\mathrm{X}$ : Endoplasmic reticulum stress in the heart: insights into mechanisms and drug targets. Br J Pharmacol 175: 1293-1304, 2018. PMID: 28548229. DOI: $10.1111 / \mathrm{bph} .13888$

28 Luo T, Chen B and Wang X: 4-PBA prevents pressure overloadinduced myocardial hypertrophy and interstitial fibrosis by attenuating endoplasmic reticulum stress. Chem Biol Interact 242: 99-106, 2015. PMID: 26428355. DOI: 10.1016/j.cbi.2015. 09.025

29 Montie HL Haezebrouck AJ, Gutwald JC and DeGracia DJ: PERK is activated differentially in peripheral organs following cardiac arrest and resuscitation. Resuscitation 66: 379-389, 2005. PMID: 16029920. DOI: 10.1016/j.resuscitation.2005.03.014

30 Ron D: Translational control in the endoplasmic reticulum stress response. J Clin Invest 110: 1383-1388, 2002. PMID: 12438433. DOI: $10.1172 / \mathrm{JCI} 16784$

31 Zhou J, Lhoták S, Hilditch BA and Austin RC: Activation of the unfolded protein response occurs at all stages of atherosclerotic lesion development in apolipoprotein E-deficient mice. Circulation 111: 1814-1821, 2005. PMID: 15809369. DOI: 10.1161/01.CIR.0000160864.31351.C1

32 Yoo SA, You S, Yoon HJ, Kim DH, Kim HS, Lee K, Ahn JH, Hwang D, Lee AS, Kim KJ, Park YJ, Cho CS and Kim WU: A novel pathogenic role of the ER chaperone GRP78/BiP in rheumatoid arthritis. J Exp Med 209: 871-886, 2012. PMID: 22430489. DOI: $10.1084 /$ jem.20111783

33 Feng B, Yao PM, Li Y, Devlin CM, Zhang D, Harding HP, Sweeney M, Rong JX, Kuriakose G, Fisher EA, Marks AR, Ron $\mathrm{D}$ and Tabas I: The endoplasmic reticulum is the site of cholesterol-induced cytotoxicity in macrophages. Nat Cell Biol 5: 781-7892, 2003. PMID: 12907943. DOI: 10.1038/ncb1035 
34 Inokuchi Y, Nakajima Y, Shimazawa M, Kurita T, Kubo M, Saito A, Sajiki H, Kudo T, Aihara M, Imaizumi K, Araie M and Hara $\mathrm{H}$ : Effect of an inducer of $\mathrm{BiP}$, a molecular chaperone, on endoplasmic reticulum (ER) stress-induced retinal cell death. Invest Ophthalmol Vis Sci 50: 334-344, 2009. DOI: 10.1167/ iovs.08-2123

35 Cırrık S, Cetinkol Y, Yıldırım A, Calgın MK and Noyan T: Circulating glucose-regulated protein 78 levels in patients with chronic hepatitis B infection. Viral Hepat J 24: 85-89, 2018. DOI: $10.4274 /$ vhd.2018.0011

36 Drazner MH: The progression of hypertensive heart disease. Circulation 123: 327-334, 2011. PMID: 21263005. DOI: 10.1161/CIRCULATIONAHA.108.845792

37 Fu HY, Okada K, Liao Y, Tsukamoto O, Isomura T, Asai M, Sawada T, Okuda K, Asano Y, Sanada S, Asanuma H, Asakura M, Takashima S, Komuro I, Kitakaze M and Minamino T: Ablation of C/EBP homologous protein attenuates endoplasmic reticulum-mediated apoptosis and cardiac dysfunction induced by pressure overload. Circulation 122: 361-369, 2010. PMID: 20625112. DOI: 10.1161/CIRCULATIONAHA.109.917914

38 Yao Y, Lu Q, Hu Z, Yu Y, Chen Q and Wang QK: A noncanonical pathway regulates ER stress signaling and blocks ER stress-induced apoptosis and heart failure. Nat Commun 8: 133, 2017. PMID: 28743963. DOI: 10.1038/s41467-017-00171-w

39 Isodono K, Takahashi T, Imoto H, Nakanishi N, Ogata T, Asada $\mathrm{S}$, Adachi A, Uyeama T, Oh $\mathrm{H}$ and Matsubara H: PARM-1 is an endoplasmic reticulum molecule involved in endoplasmic reticulum stress-induced apoptosis in rat cardiac myocytes. PLoS One 5: e9746, 2010. PMID: 20305782. DOI: 10.1371/journal. pone.0009746.
40 Khattar RS: Effects of ACE-inhibitors and beta-blockers on left ventricular remodeling in chronic heart failure. Minerva Cardioangiol 251: 143-154, 2003. PMID: 12783070.

41 Cohn JN: Cardiac remodeling: Clinical assessment and therapy, 2016. Available at: https://www.uptodate.com/contents/cardiacremodeling-clinical-assessment-and-therapy?search=Cardiac $\% 20$ remodeling:\%20Clinical\%20assessment\%20and\%20therapy\&sourc e=search_result\&selectedTitle=1 150\&usage_type=default\&display _rank=1 (Accessed June 05, 2019)

42 Ni L, Zhou C, Duan Q, Lv J, Fu X, Xia Y and Wang DW: $\beta$-AR blockers suppresses ER stress in cardiac hypertrophy and heart failure. PLoS One 6: e27294, 2011. PMID: 22073308. DOI: 10.1371/journal.pone.0027294

43 Mao W, Fukuoka S, Iwai C, Liu J, Sharma VK, Sheu SS, Fu M and Liang CS: Cardiomyocyte apoptosis in autoimmune cardiomyopathy: mediated via endoplasmic reticulum stress and exaggerated by norepinephrine. Am J Physiol Heart Circ Physiol 293: H1636-1645, 2007. PMID: 17545481. DOI: 10.1152/ajpheart. 01377.2006
Received June 9, 2019

Revised July 16, 2019

Accepted July 24, 2019 